
https://doi.org/10.30534/ijeter/2021/10942021

\title{
Analysis of the Lead-Acid Accumulators Life-time in an Electrical PV System Based on the Faradaic Efficiency
}

\author{
Kamal Hirech $^{1}$, Mustapha Melhaoui ${ }^{2}$, \\ ${ }^{1}$ LETSER Lab, Department of Physics, Faculty of Sciences, Oujda, Morocco, Hirech @ gmail.com \\ ${ }^{2}$ LSEEET Lab, Department of Physics, Faculty of Sciences \& Technics, Marrakech, Morocco
}

\begin{abstract}
In this work, we present smart tools to optimize the life-time of lead acid batteries in photovoltaic power systems. To achieve this purpose, we have developed and tested a photovoltaic electric system coupled to a battery, in which the system is equipped with an estimator of the state of charge (SoC) and another estimator of state of health $(\mathrm{SoH})$ of the batteries. The system operation is improved by using a new MPPT control approach, a charge/discharge regulator, and a human-machine interface (HMI). The experimental results of the using system have shown improvements in the operation of the electrical circuit and the optimization of the battery life-time. Indeed, the MPPT control ensure the system operation around the optimal condition, and improve their stability by taking in consideration the slightly variation of the battery voltage, the estimator of the faradic efficiency in real time led to the estimation of the $\mathrm{SoC}$ and the $\mathrm{SoH}$ and minimize the estimation error to a value of the order of $3 \%$. The charge / discharge regulator allowed a better operation of the used accumulator given the evolution of these performances as a function of the charge / discharge cycle while taking into account their characteristics. particular attention has been assigned to compare the effect of depth of discharge (DoD) on battery performance (state of health, capacity, battery life-time...) during operation. The developed system is equipped with an HMI interface developed specifically for experimentation the electrical photovoltaic installation.
\end{abstract}

Key words : Electrical installation, Grid, MPPT, State of charge, State of health Photovoltaic generator, Regulation..

\section{INTRODUCTION}

The traditional sources of electricity production have an inordinate impact on the environment pollution. however, the commitment of nations to these sources prevents the exploitation of renewable sources on a large scale [1]-[2]. Among these renewable sources, photovoltaics appears as an important alternative given their availability, their potential and their coast. The photovoltaic energy also contributes to protecting the environment by reducing the production of greenhouse gases [3]-[4]-[5].

Despite the enormous development, the photovoltaic systems suffer from many problems like the energy matching between equipment, and also PV systems can be poorly optimized reducing the energy efficiency and the life of the components / equipment, especially the accumulators [6]. These problems affect directly the maintenance process and the cost of the installations [7].

The photovoltaic system must have a very high degree of reliability to optimize the operation, the safety and the costs [8]-[9].

Any optimization of the photovoltaic installations operation must satisfy the algorithms reliability of and the control systems [10].

In this work, we present the structure, algorithms and operating results of an electrical system with a photovoltaic generator and batteries for energy storage. The results concern:

- Optimization of photovoltaic energy production by a new MPPT algorithm

- Estimation of the state of charge and the state of health [11]-[12] in order to optimize batteries lifetime.

The installation monitoring is achieved via an human-machine interface (HMI) [13]. The various electrical quantities are recovered using a serial link that connect the electrical board and the supervision software.

\section{THE ELECTRICAL INSTALLATION CONCEPTION}

\subsection{The installation structure}

We represent in figure 1 the block diagram of the stand-alone PV installation created during this work to charge two solar batteries in series $(24 \mathrm{~V})$, from two PV panels in series through a boost converter. The installation is equipped with a monitoring system based on the use of a 16F877 microcontroller. The main objective is to achieve all the following tasks in this study:

- The optimizing of the PV system operation by using our improved MPPT control.

- The real time estimating of batteries faradic efficiency, the state of charge and the state of health

- The control of the energy flow in the installation [13]. 
Kamal Hirech et al., International Journal of Emerging Trends in Engineering Research, 9(4), April 2021, 397 - 404

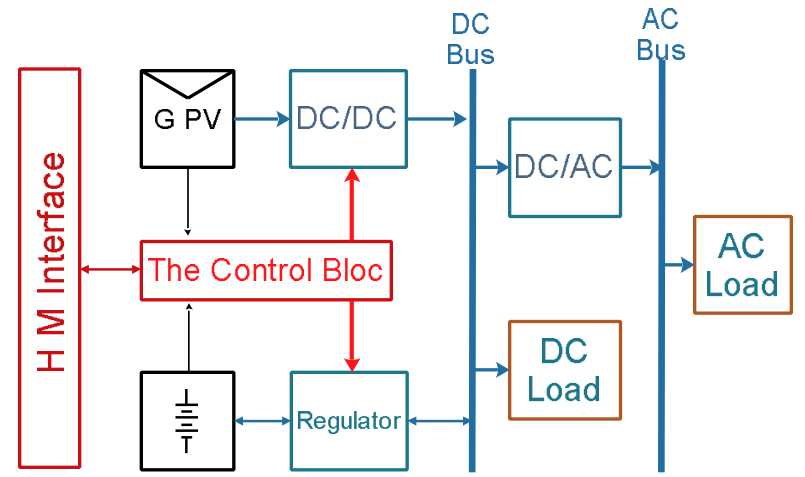

Figure 1: Synoptic diagram of the designed system

\subsection{The MPPT approach}

The optimization of the installation operation is ensured by an improved MPPT control.This technique of control consists to focus the tracking of the maximum power point (MPP) of the $\mathrm{PV}$ panels in a range of optimal voltages [ $\left.\mathrm{V}_{\mathrm{MIN}}, \mathrm{V}_{\mathrm{MAX}}\right]$ [14]. Also this approach use the condition on which the voltage of the loads / batteries is fixed or slightly variable during a short interval of time. Hense, the approach to track the MPP is realized from the equation 1 . These amounts are demonstrating that the MPP is achived when the power at the output of the converter $\mathrm{P}_{\mathrm{S}}=\mathrm{P}_{\mathrm{BAT}}$ is maximum. Since the optimization condition considers that the $\mathrm{V}_{\mathrm{BAT}}$ voltage is fixed or may varies slitghly during the charging process (a few $\mathrm{mV}$ ) we can therfore obtain the equation. 2 , which can be used to improve the MPPT algorithms in stand-alone PV systems.

$$
\begin{aligned}
& \left(\frac{d P p v}{d t}\right)_{P \max }=0 \\
& \left(\frac{d I p v}{d t}\right)_{P \max }=0
\end{aligned}
$$

The flowchart of the MPPT control is shown in figure 2. The variation of the charging current of the $\mathrm{I}_{\mathrm{BAT}}$ battery causes the variation of the duty cycle $\alpha$ of the PWM signal which controls the switch of the DC / DC converter as shown in the flowchart.

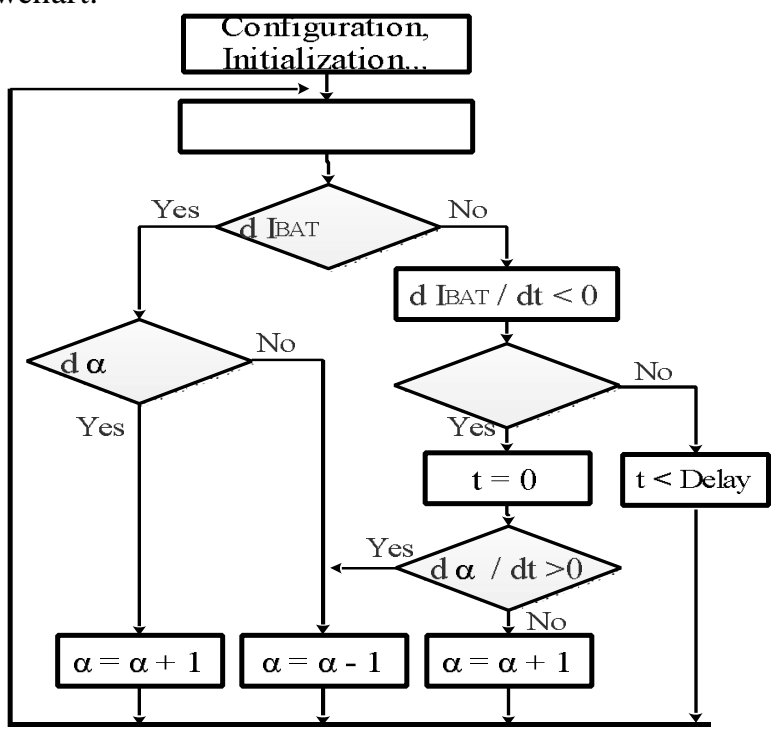

Figure 2: The MPPT organigramme

\subsection{The state of charge estimation model}

For best accuracy of the state of charge estimation SoC, we can take into consideration the Faradaic efficiency $\eta F$ [15]. The charge/ discharge process is directly related to the faradaic efficiency. This efficiency is a factor that reflects the ability of the batteries to provide a quantity of electricity Qd compared to that injected Qc. The expression is given by the equation 3. It should be noted that the quantity of charge Qc supplied to the batteries and that discharged Qd are given by the equations 4 and 5. Note, that the $\mathrm{I}_{\mathrm{BAT}}$ is the charging current and the $\mathrm{I}_{\mathrm{DECH}}$ is the discharge current.

Experimentally we calculated the faradaic efficiency from the expression of the equations 6 for a charging current equal to the discharge current

$$
\begin{aligned}
& \eta F=\frac{Q d}{Q c} \\
& Q c=I_{B A T} \times \Delta t \\
& Q d=I_{D E C H} \times \Delta t \\
& \eta F=\frac{t d}{t c}
\end{aligned}
$$

To estimate the state of charge $\mathrm{SoC}$ of batteries during the charge / discharge process, we adopted a strategy, which is mainly based on the combination of two classic methods (the OCV method and the coulomb counting method) to minimize the errors estimation of SOC during the operation of the electrical installations:

- The 1st method (OCV method), based on the use of the open circuit voltage (OCV) [16], determines the initial state of charge SoCi when the batteries are at rest from the equation 3. This equation presents the variation of the initial state of charge $\mathrm{SoCi}$ versus the open circuit voltage at $25^{\circ} \mathrm{C}$. At this temperature, an acquisition error of $\mathrm{OCV}$ voltage about $0.01 \mathrm{~V}$ causes a state of charge estimation error $(\varepsilon 1)$ that is around $0.5 \%$. Therefore, the estimation based on direct measurement requires a high measure precession. However, for the acquisition system used in this work and for the analogue to digital conversion (ADC) on $10 \mathrm{Bit}$, the acquisition voltage error can reach $0.024 \mathrm{~V}$; this causes an initial state of charge estimation error by the proposed equation with a value around $1.2 \%$.

The OCV voltage can be calculated from the electromotive force of the batteries and the variation of the voltage $\Delta \mathrm{V}$ (equation 4), this voltage (OCV) depends directly on the state of charge SoC.

$$
\operatorname{SoCi}\left(25^{\circ} \mathrm{C}\right)=(50 \times O C V)-1170+\varepsilon 1
$$

$$
O C V=E M F \pm \Delta V(S o C)
$$

(8)

- The 2nd method (Coulomb counting method), consists to determine the quantity of charge absorbed or 
Kamal Hirech et al., International Journal of Emerging Trends in Engineering Research, 9(4), April 2021, 397 - 404

supplied by the batteries during operation by the Coulomb counting method [17]. C(t) (capacity of the batteries at the $\mathrm{t}$ instant) is calculated from the nominal capacity Co and degraded capacity CDEG $(\mathrm{t})$ according to equation 9 . This parameter $\mathrm{C}(\mathrm{t})$ allows us to conclude the state of health of the batteries $\mathrm{SoH}$ which can be described by equation 10 .

$$
\begin{aligned}
& C(t)=C_{0}-C_{D E G}(t) \\
& S o H=\frac{C(t)}{C_{0}}
\end{aligned}
$$

To take into account the faradaic efficiency in the estimation of the state of charge model we have assumed that the discharge is done with a $100 \%$ of the batteries capacity, or that of loading is multiplied with the faradaic efficiency

The quantity of charge absorbed or supplied is measured by an algorithm that integrates the current of charge (SoCc (\%)) equation 11, and the current of discharge $(\mathrm{SoCd}(\%))$ equation 12 , relative to time, and taking into consideration the faradaic efficiency $\eta \mathrm{F}$ [18]. According to this method, the measurement and conversion errors will be accumulated during the integration of the charging current $\mathrm{I}_{\mathrm{BAT}}$ and discharging current $\mathrm{I}_{\mathrm{DECH}}$. These errors highly depend on the current acquisition circuit and their tolerance, well as the estimation algorithm and the speed of the system, consequently, more the error is greater, more the estimation is incorrect, hence the presence of estimation error $\varepsilon 2$ for this method. The $\operatorname{SoC}(t) a$ (added to $\mathrm{SoCi}$ ) estimated by this method is given by the equation 13 :

$$
\begin{aligned}
& \operatorname{SoCc}(t)=\left(\frac{100 \%}{C(t)}\right) \times \int \eta F \times I_{B A T}(t) \times d t \\
& \operatorname{SoCd}(t)=\left(\frac{100 \%}{C(t)}\right) \times \int I_{D E G}(t) \times d t \\
& \operatorname{SoCa}(t)=\left(\frac{100 \%}{C(t)}\right) \times \int\left(\eta F \times I_{B A T}(t)-I_{D E G}(t)\right) \times d t+\varepsilon 2
\end{aligned}
$$

In the charge / discharge process, the equation 14 gives the expression of the state of charge SoC according to the proposed method, at the $t$ instant:

$S o C(t)=S o C i+\left(\frac{100 \%}{C(t)}\right) \times \int\left(\eta F \times I_{B A T}(t)-I_{D E G}(t)\right) \times d t+\varepsilon 1+\varepsilon 2$

The compensation of errors estimation is programmed when:

- The conditions of the batteries charging end are achieved. This allows judging the rate of the batteries charging and compensating the estimation errors by calibrate the state of charge
- The batteries pass by a rest period, which stabilizes their voltage, this enables a new use of the OCV method to estimate a new SoCi, and therefore to rebalance the SoC.

The variation of temperature affects the electrical characteristics of the batteries and specifically the $\mathrm{SoC}$, then the $\mathrm{SoC}$ is determined by using equation 15 :

$$
\operatorname{SoC}(t)=\operatorname{SoC}\left(25^{\circ} C\right) \times(1+0,003 \times(T-25))
$$

\section{RESULTS AND DISCUSSION}

\subsection{Experimental procedure}

The proposed system is implemented using a digital bench. The system consists of:

- Two PV panels mounted in parallel [19],

- Two lead acid solar batteries mounted in series, each one of $12 \mathrm{~V}$ voltage with a deep of discharge (DoD) equal $60 \%$ [20].

- A DC / DC boost converter [21]

- human machine interface developed to acquire, record and trace the various electrical quantities, and also communicate with the microcontroller and manage all tests realized [22].

\subsection{The optimal operation of the PV system}

To validate the correct functioning of the MPPT control, we compared (figure 3) The results obtained by simulation on Matlab simulink and two PV installations, the 1st installation is equipped by the proposed MPPT control and 2nd one is equipped by a classical MPPT "P\&O" control.

- By comparing the two PV powers produced using the two methods control, with the optimal electrical quantities, the results show that for the proposed one; The losses are estimated at $12 \%$, while for the Classical one ( $\mathrm{P} \& \mathrm{O})$ these losses are of the order of $15.5 \%$

- The energy produced by the PV panel during this day is in the order of $244 \mathrm{Wh}$ by using the proposed Method control and is of the order of $234 \mathrm{Wh}$ by using the classical one. These values show that the energy gain provided by the new method is in the range of $3.66 \%$.

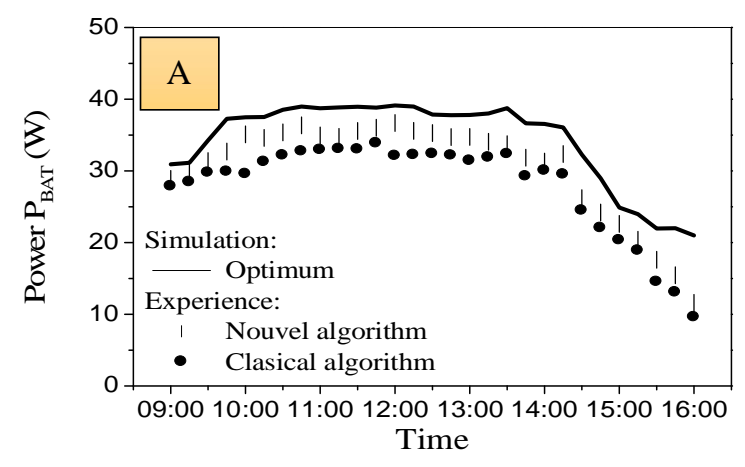


Kamal Hirech et al., International Journal of Emerging Trends in Engineering Research, 9(4), April 2021, 397 - 404

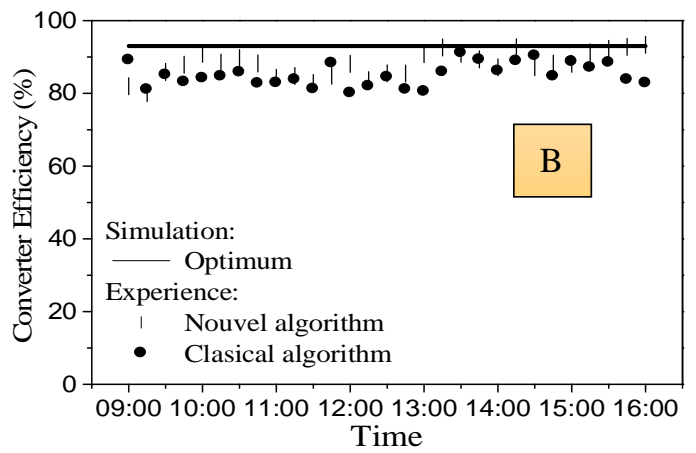

Figure 3: comparison of, A: power and, B: efficiency for the two techniques of MPPT controls

\subsection{The faradaic efficiency evaluation}

\section{A. The charging mode influence on faradaic efficiency.}

To estimate the state of charge of lead acid batteries it was necessary to study the behavior of the faradaic efficiency following the different modes of operation.

In this paragraph we have tried to study the evolution of faradaic efficiency as a function of the discharging current. For this, we have discharged the solar battery using different current values in a resistive DC load.

The table 1 presents the experimental results obtained during this study. These results show that:

- The real recoverable capacity from the battery depends strongly on the discharge current. This capacity decreases if the discharging current increases. Thus, the nominal capacity can only be evaluated for discharge currents of very low value (of the order of $\mathrm{C} / 100$ ).

- For the discharge currents of low value (C / 100), the faradaic efficiency is around $100 \%$, but this value decreases with the increase of discharging current, this has caused that the battery cannot absorb the current supplied.

Table 1: The discharge characteristics of the used battery at varying rates of discharge at $30^{\circ} \mathrm{C}$.

\begin{tabular}{|c|c|c|c|c|}
\hline & $\begin{array}{c}\text { Full } \\
\text { discharge } \\
\text { time (h) }\end{array}$ & $\begin{array}{c}\text { Discharge } \\
\text { current } \\
\text { (A) }\end{array}$ & $\begin{array}{c}\text { Capacity } \\
\text { available } \\
\text { (Ah) }\end{array}$ & $\begin{array}{c}\text { Faradaic } \\
\text { efficiency } \\
(\%)\end{array}$ \\
\hline C1 & 1 & 110 & 30 & 30 \\
\hline C2 & 2 & 55 & 34 & 33 \\
\hline C3 & 3 & 36,6 & 38 & 36 \\
\hline C4 & 4 & 27,5 & 40 & 40 \\
\hline C5 & 5 & 22 & 45 & 44 \\
\hline C10 & 10 & 11 & 60 & 58 \\
\hline C20 & 20 & 5,5 & 74 & 70 \\
\hline C50 & 50 & 2,2 & 83 & 84 \\
\hline C100 & 100 & 1,1 & 110 & 100 \\
\hline
\end{tabular}

The method of charging the batteries affects the faradaic efficiency, for the focus of this influence we have charged the two batteries of the same type and with the same state of health. The first one with a charge discharge regulation system. However, the 2 nd battery one without regulator. We present in figure 4 the results obtained. These results concern the evolution of the faradaic efficiency of the two cases as function of the state of charge SoC. They show that:

- For the battery with a regulation system, the faradaic efficiency is more stable and closer to $97 \%$ at the start of charging. This value begins to decrease as the value of SoC increases. The faradaic efficiency value is close to $60 \%$ at the end of the charge $(\mathrm{SoC}=100 \%)$. The average value during all the charging phases is around $85 \%$.

- Concerning the 2nd battery, it's charged with the maximum current supplied. at the beginning, the value of the faradaic efficiency is around $95 \%$, however and with the increase of the voltage and the state of charge this efficiency decreases because the battery cannot absorb all the current supplied; a part of this current is consumed by parasitic reactions or/and dissipated by joule effect in the battery. The efficiency decreases further with the increase of the state of charge. At the end of charging process, its value of the faradaic effeciency reaches $25 \%$ and the average value of this efficiency during the charging mode is of the order of $66 \%$.

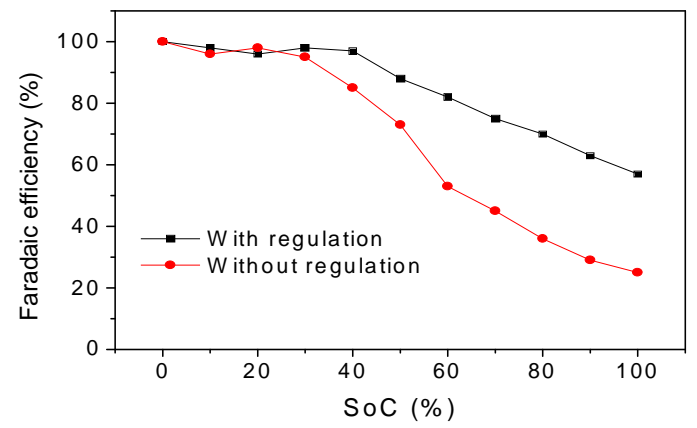

Figure 4: The Variations of the faradaic efficiency as function of the state of charge estimation

\section{$B$. The battery state and the evolution of faradaic efficiency.}

In order to evaluate the influence of the battery state on faradaic efficiency we have operated the battery during several cycles of charge / discharge (over 300) while recovering the faradaic efficiency value during the operation. The figure 5 presents the results obtained concerning the evolution of the faradaic efficiency as a function of the cycles number of discharge/charge (Figure 5.A), and according to the state of health (Figure 5.B). These figures show that the increase of cycles number of charge/discharge process causes aging of the battery and decrease the faradaic efficiency. The value of this efficiency is around $100 \%$ when the battery is new $(\mathrm{SoH}=100 \%)$, but with the degradation and the aging phenomenon; the faradaic efficiency decreases and its value approaches from $0 \%$ (when the battery is died). 

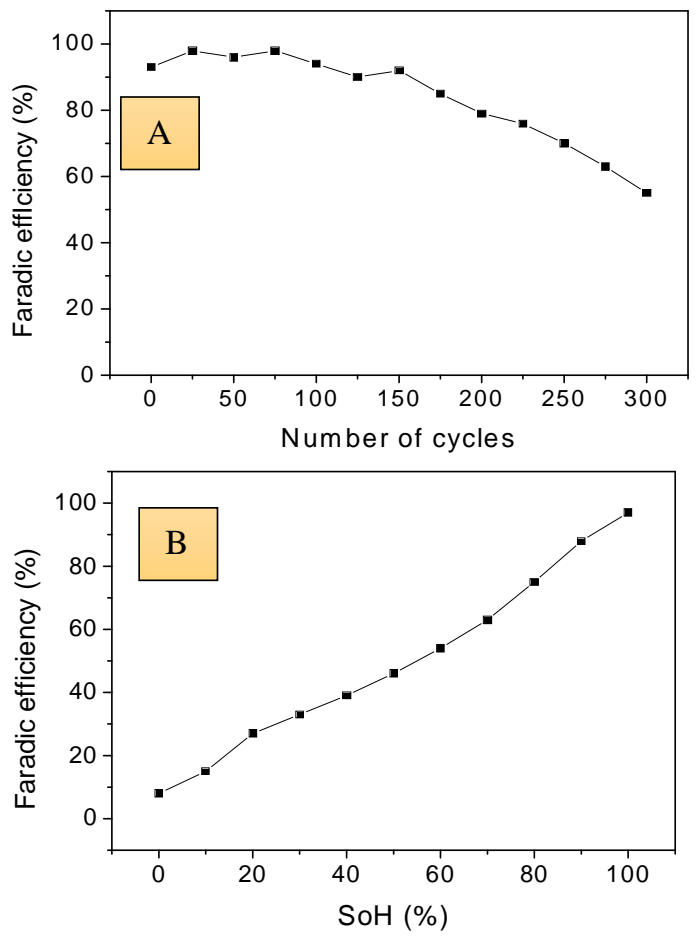

Figure 5: The Variations of the faradaic efficiency as function of: A. number of cycles charge/discharge, B. state of health $\mathrm{SoH}$

\subsection{The state of charge estimation}

We have charged the batteries used in this study completely for 5 days of experimentation, and we have estimated the state of charge by two methods: the first one is the OCV method (conventional) that consists to estimate the $\mathrm{SoC}$ when the batteries are in a state of rest [23]. The second method is presented and detailed in this study and by taking into the count the faradaic efficiency results obtained in the last paragraph. The results produced by these two methods are compared to SoC estimation provided by the manufacturer of the solar batteries used (ideal SoC), depending on their type, temperature and voltage; this is for periods of rest that are greater than 24 hours.

In figure 6.A we represent the state of charge estimation by the proposed method, the OCV method after the battery rest of 12 hours and the ideal SoC provided by the manufacturer. In figure 6.B we present the estimation error of each method, and the figure 6.C present the difference in $\%$ between the proposed method and the conventional one (OCV), these results show:

- The proposed method can estimate the state of charge of the batteries in real time. This estimation is non-linear relative to time; this is explained by the fact that the irradiance changed when the quantity of charge absorbed by the batteries during the experimental periods changed also. Contrary, the OCV method can be used only if the battery voltage has stabilized

- Either methods, the proposed and the OCV present a SoC estimation errors. The errors introduced by the proposed one are of the order of $3 \%$ this value decreases remarkably in the end of charging. However, the OCV method presents an error considerably higher in estimation (average value of the order of 5.5\%). The errors depend on voltage value stabilization.

- The difference in the estimation between the OCV and the proposed methods compared to the ideal SoC (figure 8.C) can reaches a value around $2 \%$ at the beginning of charging, this value increase with time and reaches a value in the range of $6 \%$ due to estimation errors that accumulate and committed by the OCV method. The SoC estimation by the proposed method is always close to the ideal one. Hence, an average improvement contributed in estimating.

These results show that the proposed method allows estimating the SoC dynamically and with precision. Consequently, optimizes the charge/discharge process and improve the of life-time of the batteries.
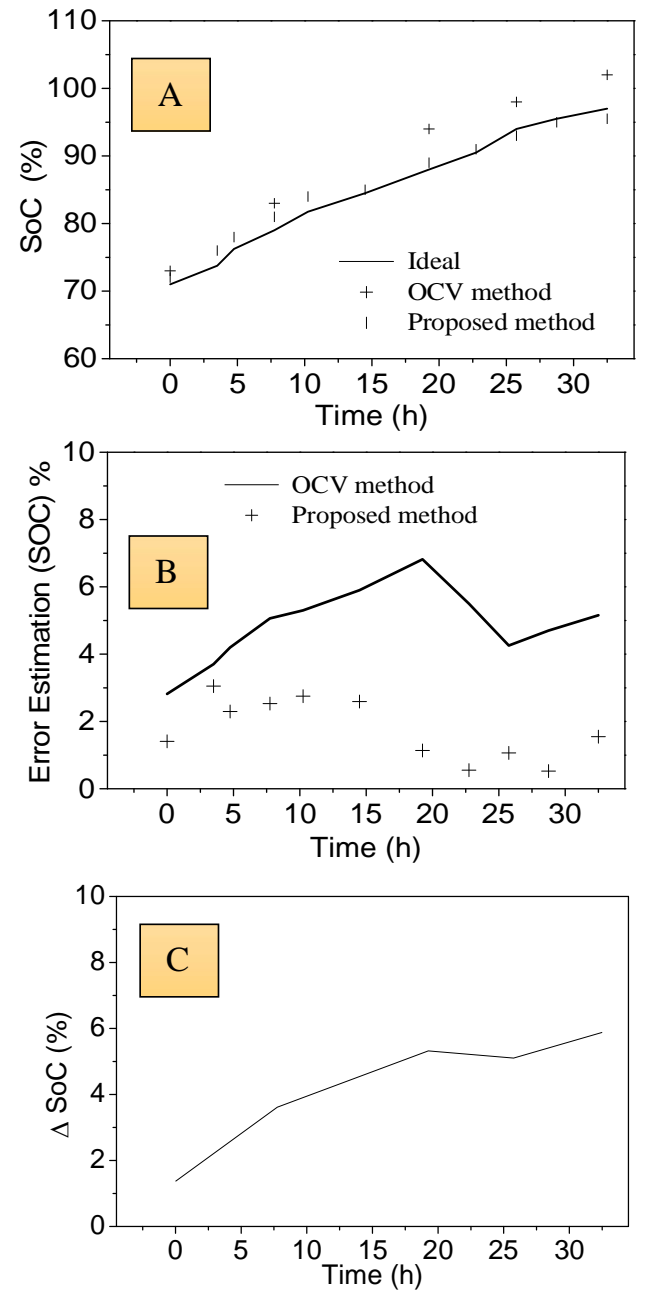

Figure 6: The Variations of: A. SoC, B. errors estimation, C. difference in the estimation of SoC between the OCV and the proposed method compared to the ideal SoC

\subsection{Optimization of the lead acid batteries life-time}

\section{A. The process description.}

We have experimented the two batteries (the same type and the same state) during several charge/discharge cycles in order to estimate the evolution of the capacity degradation 
Kamal Hirech et al., International Journal of Emerging Trends in Engineering Research, 9(4), April 2021, 397 - 404

during the operation and to conclude the state of health $\mathrm{SoH}$ evolution.

The first battery (BAT1) was charged / discharged regularly with the regulation system. This system takes into consideration the characteristics of the lead batteries and estimates the state of charge SoC from the proposed method. For the battery BAT1, the system stops the discharge at $40 \%$ $(\mathrm{DoD}=60 \%)$. However, the second battery was charged / discharged using a commercial regulator which controls and stops the discharge when the state of charge $\mathrm{SoC}$ reaches a value of $20 \%$ ( $\mathrm{DoD}=80 \%)$. Then, the two batteries will be discharged through a resistive load by the same current (5A).

\section{B. Degradation of batteries capacity.}

We present in the figure 7 the experimental results the evolution of: the capacity, the $\mathrm{SoH}$ and the capacity losses of the two batteries in relation to the charge/discharge cycle carried out. These results show that:

- In the case of both regulation systems, both batteries lose capacity due to the exploitation and the aging (charging / discharging cycles). Knowing that the first regulation system (for BAT1) stops the discharge at $60 \%$ to protect the battery against deep discharges. However, the second (for BAT2) continues the discharge until reaching 20\% of the $\mathrm{SoC}(\mathrm{DoD}=80 \%)$.

- After 50 charging / discharging cycles, the 1st battery (BAT1) has a SoH of 0.92 (92\%). It lost $8 \%$ of its initial capacity, however the second had a state of health of 0.9 $(90 \%)$ and it lost $10 \%$ of its initial capacity. At 100 cycles, the 1st battery (BAT1) lost $16 \%$ against $24 \%$ for the 2 nd battery (BAT2). So, the BAT2 loses capacity faster than BAT1. Consequently, the battery BAT1 continues to keep its good state of health and it can continue its operation without difficulty until a cycle number estimated at 300 cycles. However, the user should consider changing the 2nd battery to approximately 200 cycles of operation.

The good control and management of charge / discharge cycles by sophisticated regulation systems that take into consideration, in particular, the characteristics of the batteries allow extending their life-time by optimizing the operation and the charge / discharge cycles number that can perform.

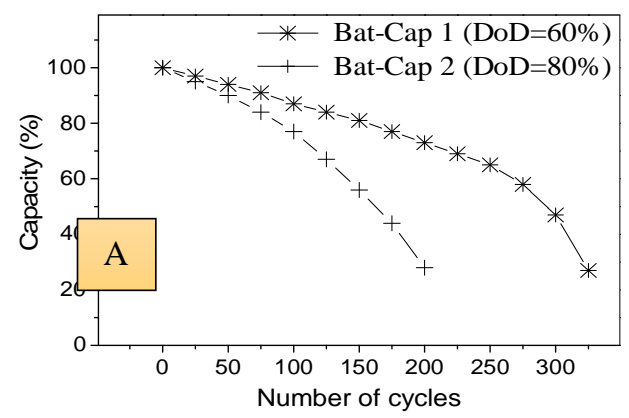

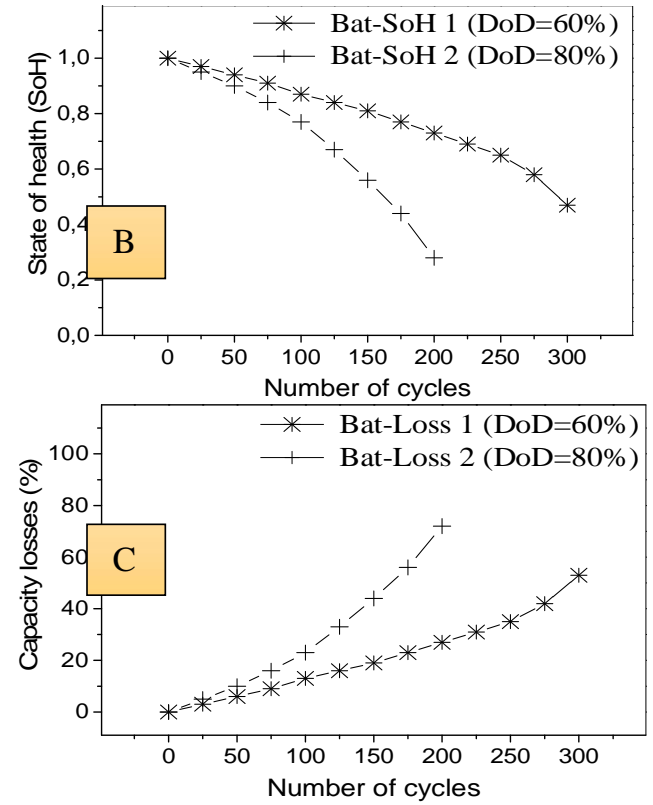

Figure 7: The evolution of, A. the capacity, B. the state of health, C. the capacity losses in relation to the number cycles

C. The impact of the optimization on investment cost and environment.

The Figure 8 shows the evolution of the autonomy and of the energy stored as a function of the charge / discharge cycle for the two batteries studied during 300 operating cycles under the same conditions. the batteries concerned are characterized by an initial energy stored in each of them equal to $1.3 \mathrm{kWh}$. Thus, for a daily consumption profile of $0.1 \mathrm{KWh}$, the regulation system (for BAT1) guarantees an autonomy of 8 days (the discharge stops at $40 \%$ and $0.8 \mathrm{kwh}$ of energy can be discharged). Against an autonomy of 10 days for the commercial system (the discharge stops at $20 \%$ and $1 \mathrm{kwh}$ of energy can be discharged). Then, during one year of operation the battery BAT1 makes 45 cycles against 36 cycles for the battery BAT2 (The commerce regulation system). In addition, the batteries capacity degrades with the use (increase of the charging / discharging cycles number); it is noted that at 100 cycles the BAT1 is degraded by $16 \%$, so it can only provide $0.6 \mathrm{KWh}$ by cycle and its autonomy is reduced to 6 days. Against a degradation of $24 \%$ for BAT2, which can provide only $0.74 \mathrm{KWh}$ and its autonomy reduced to 7 days.

Based on the calculation of the average energy that the battery can provide during its life (300 cycles for the BAT1 and 200 for the BAT2) before it will be considered dead, (the battery was declared dead when the capacity has dropped to about half of its initial value [24]). It is concluded that: The BAT1 can provide an average energy during each cycle of $0.5 \mathrm{KWh}$ against $0.59 \mathrm{KWh}$ for the BAT2. Where the average autonomy for the BAT1 of 5 days against 5.9 days for the BAT2. From these results and since the BAT1 will be able to operate during 300 cycles against 200 cycles for the BAT2; in 20 years of the installation operation the 1st battery BAT1 must perform 1460 cycles, against 1240 cycles for the 2nd battery BAT2 in order to satisfy the same energy demand. As a result, 
the BAT1 should be changed almost 5 (4.8 times) against to more than 6 (6.2) times for the BAT2.

The optimization of operation and the life-time of the batteries allows reducing the number of batteries acid-plomb to be changed in the installation and the cost by $23 \%$. Consequently, reducing the use of toxic metals such as lead in the manufacture. This automatically reduces the risk of pollution and poisoning by heavy metals.

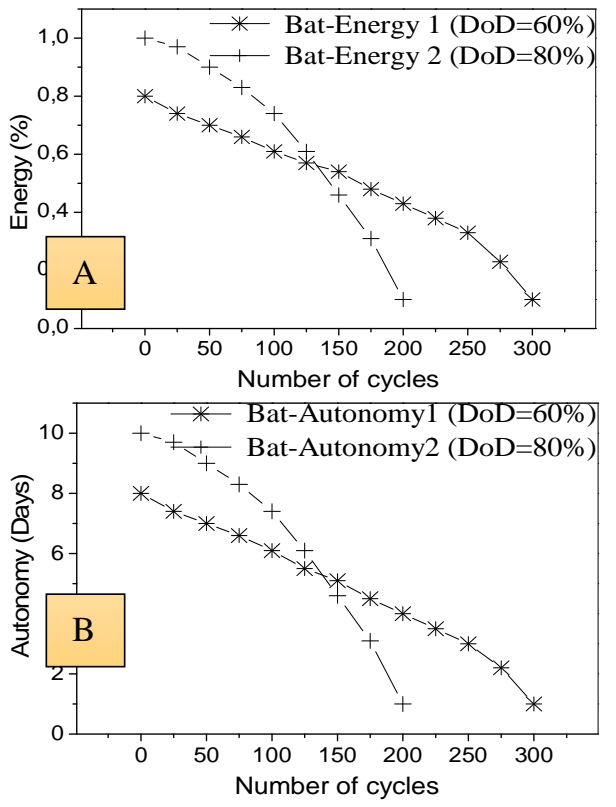

Figure 8: The evolution of, A. batteries energy, B. autonomy in function of charge / discharge cycles.

\section{CONCLUSIONS}

In this work, we studied an electrical installation equipped with a photovoltaic generator and batteries for the storage of energy. The experimental results obtained show:

- Good control of the different blocks of the installation (converter, charge/ discharge, energy management)

- The acquisition and supervision system allowed the good communication with the electrical / electronic cards.

- The MPPT control allowed the stabilization and optimization of energy production under good converter yields.

- problems of estimation errors and the charging / discharging process, thus maximizing battery life-time and Therefore, automatically reduce the risk of pollution and intoxication by heavy metals in batteries and investment costs.

From the results presented and discussed in this work, we have demonstrated the feasibility of the methods developed and the simplicity of their implementations, all to maximize the energy production, to optimize the installation operation and to reduce the investment cost.

\section{REFERENCES}

1. FURLAN, Claudia et MORTARINO, Cinzia. Forecasting the impact of renewable energies in competition with non-renewable sources. Renewable and Sustainable Energy Reviews, 2017.

2. SAMPAIO, Priscila Gonçalves Vasconcelos et GONZÁLEZ, Mario Orestes Aguirre. Photovoltaic solar energy: Conceptual framework. Renewable and Sustainable Energy Reviews, 2017, vol. 74, p. 590-601.

3. MENIA, Sabah, TEBIBEL, Hammou, LASSOUANE, Fatiha, et al.Hydrogen production by methanol aqueous electrolysis using photovoltaic energy: Algerian potential. International Journal of Hydrogen Energy, 2017, vol. 42, no 13, p. 8661-8669.

4. SAMPAIO, Priscila Gonçalves Vasconcelos et GONZÁLEZ, Mario Orestes Aguirre. Photovoltaic solar energy: Conceptual framework. Renewable and Sustainable Energy Reviews, 2017, vol. 74, p. 590-601.

5. LUDIN, Norasikin Ahmad, MUSTAFA, Nur Ifthitah, HANAFIAH, Marlia M., et al. Prospects of life cycle assessment of renewable energy from solar photovoltaic technologies: A review. Renewable and Sustainable Energy Reviews, 2018, vol. 96, p. 11-28.

6. PATRICK, Caleb Aaron. Technical feasibility and life cycle cost assessment of a photovoltaic array on Trinity Dam, Trinity County, CA. 2018.

7. TIAN, Lixin, PAN, Jianglai, DU, Ruijin, et al. The valuation of photovoltaic power generation under carbon market linkage based on real options. Applied energy, 2017, vol. 201, p. 354-362.

8. ABDULLA, Khalid, DE HOOG, Julian, MUENZEL, Valentin, et al. Optimal operation of energy storage systems considering forecasts and battery degradation. IEEE Transactions on Smart Grid, 2018, vol. 9, no 3, p. 2086-2096.

9. Adurodija, F. O., Asia, I. O., \& Chendo, M. A. C. (1998). The market potential of photovoltaic systems in Nigeria. Solar energy, 64(4-6), 133-139.

10. Saini, G., \& Baghini, M. S. (2019). A generic power management circuit for energy harvesters with shared components between the MPPT and regulator. IEEE Transactions on Very Large Scale Integration (VLSI) Systems, 27(3), 535-548.

11. XIONG, Rui, YU, Quanqing, et SUN, Fengchun. A study on the inflence of two OCV tests on state of charge estimation of lithium ion battery. In : Industrial Electronics and Applications (ICIEA), 2017 12th IEEE Conference on. IEEE, 2017. p. 608-612.

12. BERECIBAR, M., GANDIAGA, I., VILLARREAL, I., et al. Critical review of state of health estimation methods of Li-ion batteries for real applications. Renewable and Sustainable Energy Reviews, 2016, vol. 56, p. 572-587.

13. Herceg, S., Pinto Bautista, S., \& Weiß, K. A. (2020). Influence of waste management on the environmental 
footprint of electricity produced by photovoltaic systems. Energies, 13(9), 2146.

14. Guo, B., Su, M., Sun, Y., Wang, H., Liu, B., Zhang, X., ... \& Davari, P. (2020). Optimization Design and Control of Single-Stage Single-Phase PV Inverters for MPPT Improvement. IEEE Transactions on Power Electronics, 35(12), 13000-13016.

15. MA, Jin-Ling, BAO, Di, SHI, Miao-Miao, et al. Reversible nitrogen fixation based on a rechargeable lithium-nitrogen battery for energy storage. Chem, 2017, vol. 2, no 4, p. 525-532.

16. XING, Yinjiao, HE, Wei, PECHT, Michael, et al. State of charge estimation of lithium-ion batteries using the open-circuit voltage at various ambient temperatures. Applied Energy, 2014, vol. 113, p. 106-115.

17. SEPASI, Saeed, GHORBANI, Reza, et LIAW, Bor Yann. A novel on-board state-of-charge estimation method for aged Li-ion batteries based on model adaptive extended Kalman filter. Journal of Power Sources, 2014, vol. 245, p. 337-344.

18. MANOHAR, Aswin K., KIM, Kyu Min, PLICHTA, Edward J., et al.Evaluation of the Performance of an Iron-Chloride Redox Flow Battery for Large Scale Energy Storage. In : Meeting Abstracts. The Electrochemical Society, 2015. p. 683-683.

19. López, J., Seleme Jr, S. I., Donoso, P. F., Morais, L. M. F., Cortizo, P. C., \& Severo, M. A. (2016). Digital control strategy for a buck converter operating as a battery charger for stand-alone photovoltaic systems. Solar Energy, 140, 171-187.

20. Mirbagheri, S. Z., Mekhilef, S., \& Mirhassani, S. M. (2013). MPPT with Inc. Cond method using conventional interleaved boost converter. Energy Procedia, 42, 24-32.

21. Lakshmi, M., \& Hemamalini, S. (2017). Nonisolated high gain DC-DC converter for DC microgrids. IEEE Transactions on Industrial Electronics, 65(2), 1205-1212.

22. Sampaio, P. G. V., \& González, M. O. A. (2017). Photovoltaic solar energy: Conceptual framework. Renewable and Sustainable Energy Reviews, 74, 590-601.

23. XIA, Bing, SHANG, Yunlong, NGUYEN, Truong, et al. A correlation based fault detection method for short circuits in battery packs. Journal of Power Sources, 2017, vol. 337, p. 1-10. 